\section{Optimal setting and care organization in the management of older adults with hip fracture: a narrative review}

\author{
Andrea Giusti, Antonella Barone, \\ Monica Razzano, Rita Raiteri, \\ Andrea Del Rio, Viviana Bassoli, \\ Ernesto Palummeri, Mauro Oliveri, \\ Alberto Pilotto \\ Department of Orthogeriatrics, \\ Rehabilitation and Stabilization, \\ Frailty Area, Galliera Hospital, \\ National Relevance and Specialization \\ Hospital, Genoa, Italy
}

\section{Abstract}

Hip fracture (HF) is a common event in older adults and is associated with significant morbidity, mortality, reduction of quality of life and costs for the healthcare systems. The expected rise in the total number of $\mathrm{HF}$ worldwide, due to improvements in life expectancy, and the growing awareness of $\mathrm{HF}$ detrimental consequences have led to the development and implementation of models of care alternative to the traditional ones for the acute and post-acute management of $\mathrm{HF}$ older adults. These services were set to streamline hospital care, minimize inhospital complications, provide early discharge, improve short- and long-term functional and clinical outcomes, and reduce healthcare costs associated with hip and other fragility fractures. The main feature that distinguishes these models is the different healthcare professional that retains the responsibility and leadership during the acute and post-acute phases.

This narrative review has been conceived to provide a brief description of the models implemented in the last twenty years, to describe their potential beneficial effects on the shortand long-term outcomes, and to define the strengths and limitations of these models. On the basis of available studies, it seems that the more complex and sophisticated services, characterized by a multidisciplinary approach with a co-leadership (geriatrician and orthopedic surgeon) or a geriatrician leadership demonstrated to produce better outcomes compared to the traditional or simplest models.

\section{Introduction}

Osteoporotic fractures are common events in older adults, both in females and males. Their incidence increases exponentially with age, becoming a serious and disabling healthcare issue especially in frail older adults due to their greater vulnerability. Among fragility fractures, hip fracture (HF) represents the one associated with the most dramatic outcomes, being related with significant morbidity, mortality, disability, deterioration of quality of life and costs for the healthcare systems. ${ }^{1-3}$ Total one-year mortality is impressive, ranging between $14 \%$ and $36 \%{ }^{1}$ In addition, observational studies have reported a high rate (up to 15\%) of permanent institutionalization at 12 months post-injury in surviving community-dwelling patients. ${ }^{1,2}$

The growing awareness of the detrimental consequences of hip and other fragility fractures and the expected rise in the total number of osteoporotic fractures worldwide have led to the development and implementation of models of care alternative to the traditional ones for the acute and post-acute management of fractured older adults. ${ }^{4,5}$ These services were set to minimize in-hospital complications, streamline hospital care and provide early discharge with the primary objectives of improving survival, functional and clinical outcomes, and reducing the direct and indirect healthcare costs associated with hip and other osteoporotic fractures.

The main features that distinguish these innovative models of care from the traditional ones are the different healthcare provider that retains the responsibility of the care during the acute and post-acute phases, the skilled multidisciplinary team of healthcare professionals, and the organization of the orthogeriatric service/unit. ${ }^{4,5}$

To date, on the basis of available studies, it is not possible to define the best model of care for fractured older adults. However, the more complex and sophisticated services, characterized by a multidisciplinary approach, demonstrated, in randomized-controlled trials (RCTs), beforeafter observational studies and two meta-analyses, to produce better outcomes compared to the traditional or simplest models. ${ }^{4-8}$

In this narrative review we provide a brief description of the models implemented in the last twenty years, we describe their potential benefits on short- and long-term outcomes, we define the strengths and limitations of these models and we highlight the areas of uncertain, making some considerations about the future of orthogeriatric care.

\section{General considerations: issues related to the setting and care organization}

\section{Responsibility and leadership: who is in charge?}

The multidisciplinary approach is now the gold standard in the healthcare of older adults
Correspondence: Andrea Giusti, Department of Orthogeriatrics, Rehabilitation and Stabilization, Frailty Area, Galliera Hospital, via Mura della Cappuccine 14, 16129 Genoa, Italy.

Tel.: +39.010.5634395 - Fax: +39.010 .5434400 .

E-mail: andrea.giusti@galliera.it

Key words: Hip fracture; orthogeriatric; aged.

Contributions: $\mathrm{AB}$ and $\mathrm{AG}$ equally contributed in the concept and design of the study, and in the preparation of the first draft of the manuscript; MR, RR, ADR, VB, MO and EP contributed in the literature search and in the critical review of the manuscript for relevant intellectual contents; AP contributed in the concept, design and critical review of the manuscript.

Conflict of interest: AG has received honoraria and/or consulting fees from Eli Lilly, Merck and Co., Amgen, Chiesi, Abiogen Pharma and Dynamicom (CME provider). The other Authors declare no conflict of interest.

Received for publication: 25 October 2015 .

Revision received: 7 November 2015.

Accepted for publication: 10 November 2015.

This work is licensed under a Creative Commons Attribution-NonCommercial 4.0 International License (CC BY-NC 4.0).

(C) Copyright A. Giusti et al., 2015

Licensee PAGEPress, Italy

Geriatric Care 2015; 1:5602

doi:10.4081/gc.2015.5602

presenting with hip or other osteoporotic fractures. The basic interdisciplinary team of orthogeriatric models includes the orthopedic surgeon and the geriatrician, supported by the anesthesiologist in the peri-operative phase and other healthcare providers, such as physiotherapist, clinical nurse, nutritionist and social worker, during the acute and post-acute phases. ${ }^{4,5}$ Scheduled meetings and written orders are the usual way to share information and to communicate between team members. In some experiences, a skilled care manager takes on the role of coordinating the pathway of care and fostering communications between professionals. $^{9}$

The main feature that distinguishes the huge variety of orthogeriatric models implemented to date concerns the healthcare professional that retains the responsibility throughout the care pathway. ${ }^{4,5}$ In the geriatric consultant model, as well as in the traditional one, the overall responsibility of the care is under the orthopedic surgical staff. The geriatricorthopedic co-managed care model is characterized by the co-management of the patients by the geriatrician and the orthopedic surgeon that share the responsibility and leadership. Finally, the geriatrician leadership distin- 
guishes the third model, usually referred as geriatric-led fracture service.

\section{Comprehensive geriatric assessment approach in orthogeriatric care}

Orthogeriatric care was primarily involved in the care and management of fragility hip fractures, but it has recently been expanded to provide specialist care to patients admitted with other various fractures. While comprehensive geriatric assessment (CGA)-based inpatient geriatric consultation service has shown little benefit, the co-management with a geriatrician may be beneficial for hip fracture patients in reducing complications, mortality, readmissions, and delirium. ${ }^{10-12}$ A systematic review conducted on 56 studies suggested that age and cognitive impairment were the best CGA-based predictors of long-term care placement after hip fracture. ${ }^{13}$ Predictors of increased mortality in long-term care residents after hip fracture were age, male gender, disability, coronary artery disease, pre-surgery anemia, pressure ulcers, and pneumonia, while predictors of subsequent fracture were higher function level, previous fracture, and previous falls. ${ }^{13}$

In conclusion, CGA methodology is an effective and crucial approach to optimize the beneficial effect on short- and long-term outcome of the orthogeriatric model for the management of the older patients with hip fractures. ${ }^{14}$

\section{Time to surgery}

Recent data support the beneficial effect of early surgery in the management of older adults presenting with hip fracture. Although the meaning of early surgery is still debated, guidelines and recognized experts suggest that fit patients should undergo surgery as soon as feasible, while those unfit should be quickly optimized to avoid detrimental delays. ${ }^{5,15}$

The recognition of HF as a clinical emergency requiring early surgery has significantly affected the organization and implementation of the orthogeriatric models. In an ideal model, the patient should be transferred directly to the surgical theatre from emergency department, and admitted to a hospital ward only after surgical repair. The feasibility of this approach has been tested in a study undertaken at the PitiéSalpetriere Hospital (Paris), where the hip fractured patients, following a fast track procedure, were quickly operated and, only postoperatively, were admitted to a dedicated Geriatric Unit. ${ }^{16}$ Indeed, this approach needs a more complex and coordinated organization and it is, therefore, at least in part still theoretical. However, we feel that a model of care based on the fast track in the emergency department and on the emergency surgery will affect significantly the development of orthogeriatric units in the close future. ${ }^{5}$

\section{Length of hospital stay, early and late rehabilitation}

In the various countries, the orthogeriatric models of care have been also influenced by the need of reduce acute in-hospital stay and promote early discharge to rationalize the resources. On the other hand, early discharge is affected by the availability of post-acute rehabilitation facilities in the community. Therefore, even when strategies to reduce the length of hospital stay (LOS) are implemented, LOS is largely dependent on the features of the healthcare system, and often related to local organizational factors.

In general, there is an inverse relationship between LOS and rate of transfer to rehabilitation services in the community. The models characterized by short in-hospital stay (between 5 and 7 days) should be supported by the presence of adequate post-acute rehabilitation services, able to take care of the patients undergoing early discharge and community rehabilitation. ${ }^{16-20}$ In this scenario up to $70 \%$ of hip fracture older adults are usually transferred to inpatient rehabilitation or community skilled-nursing facilities to continue rehabilitation. On the other hand, when the service is organized to commence and continue rehabilitation into the Hospital, the LOS usually exceed 20 days, and most of the patients complete the rehabilitation phase during in-hospital stay, with only a very few proportion of them (less than 20\%) transferred to other community services for further rehabilitation/healthcare. ${ }^{21-24}$

In the middle of these two scenarios, there are the majority of European models. In European countries, usually, the LOS ranges between 10 days and 15 days, with the rehabilitation broken down in two phases: an early phase that occurs during in-hospital stay, and later one that takes place after the discharge in the community. ${ }^{25-33}$

\section{Hospital volumes and expertise in managing hip fracture}

Kates and colleagues have suggested that there should be a reasonable volume of hip fractures per year to develop sufficient expertise in managing hip fracture patients and to implement an innovative model of care. ${ }^{4,34}$ Nowadays, there is no evidence to suggest a precise number of hip fracture cases per year, although it is believed that approximately 100 patients per year could be a reasonable volume to make these programs effective. ${ }^{34}$

A positive relationship between provider volume and outcomes has been shown for a wide range of surgical procedures across a variety of specialties. Particularly, higher surgeon and hospital procedure volumes have been associated with lower mortality rates, fewer complications and shorter LOS. ${ }^{4}$
In the case of hip fracture, two recent studies reported conflicting results. ${ }^{4,35,36}$ Forte et al. demonstrated a higher inpatient and 30-day mortality in subjects managed at lower-volume hospitals (less than 27 cases per year) compared to those treated in highest-volume hospitals (28 or more cases per year) in a study carried out in the US, considering more than 192,000 elderly patients presenting with intertrochanteric $\mathrm{HF}^{36}$ In a study from Finland, Sund did not find a clear relationship between hospital volume and mortality, while reported an association between the rehabilitation unit volume and 4-month mortality. ${ }^{35}$

In conclusion, summarizing available evidence a number of considerations may be drawn: i) a high number of cases per year is needed to implement an orthogeriatric service for the management of HF older adults, since in low-volume hospitals such services may not produce the expected benefits, but a defined number cannot be outlined; ii) not only the acute care ward volume but also the rehabilitation unit volume may be relevant; iii) the concentration of HF services in high-volume hospitals may have significant implications in the (re)distribution of resources, (re)organization of healthcare and costs in developed countries. ${ }^{4}$

\section{Models of integrated care}

\section{General considerations}

Innovative models of care for the management of older orthopedic patients, particularly hip fracture older adults, have been developed since more than 30 years ago, with the first RCT comparing a traditional model with an orthopedic-geriatric inpatient service published by Gilchrist et al. in $1988{ }^{37}$

In the traditional model, the fracture patient was admitted to a trauma ward, where the orthopedic surgeon was responsible for the care of the patient, medical queries and complications were dealt by consultative medical services, and the physician's opinion was required only when the surgeon considered it desirable. ${ }^{4,5,8}$ In the post-acute phase, early rehabilitation took usually place within the orthopedic ward. After discharge, the patient could be transferred directly home, to a community nursing facility or to a rehabilitation facility, without substantial continuity of care.,5

The first models introduced were simple variations of the traditional one. They were characterized by regular inputs from a specific trained consultant team including several healthcare professionals, with the overall responsibility of the care under the orthopedic surgical staff. ${ }^{4}$ Over the years these models developed, being replaced by multidisciplinary and coordinated approaches that demonstrated to be more effective to meet patients' com- 
plex needs. ${ }^{4}$ These experiences have been designated with different names, such as ortho-geriatric units, co-managed geriatric fracture centers (GFC), or geriatric hip fracture clinical pathway, which in most of the cases, but not always, distinguished dissimilar models in terms of setting and organization. However, the basic idea underlying the development of the se projects was quite always the same: the definition of a multidisciplinary team dedicated to the care of the fractured older adult, to promote continuity of care, rapid management and/or prevention of the potentially undercurrent medical problems, early mobilization and rehabilitation, and coordinated discharge planning. ${ }^{4,5}$

Although a variety of experiences have now been described, the alternative services reported in the available literature can be broken down into 3 main models: ${ }^{4,5}$ i) geriatric consultant in the orthopedic ward; ii) geriatricorthopedic co-managed care; and iii) geriatricled fracture service with orthopedic consultant (Table 1).

\section{Geriatric consultant in the orthopedic ward}

This is a variation of the traditional model, being one of the first services implemented in different developed countries. ${ }^{4,5,8}$ The main features that characterize the model are: i) the overall responsibility under the orthopedic surgical staff; ii) the designation of a geriatric team (including several healthcare professionals) for the management of the patients during the acute and post-acute phases; iii) the regular input by the consultant team; iv) the implementation of early discharge programs. The consultant team contribution could start early from hospital admission or lately postoperatively. The team holds weekly or more frequent rounds to develop and monitor treatment plans. The prevention and management of common problems/complications of elderly patients with fracture are based on the choices of the individual surgeon or physician. The orthopedic surgeon settles early mobilization, discharge timing and location.

In observational studies and RCTs, this model did not demonstrate to produce significant beneficial effects, compared to usual care, on the length of hospital stay, mortality, recov- ery of ambulation and functional abilities, when the consultant team contribution started postoperatively. ${ }^{4,5}$ Slightly better results were reported when the consultant team participated early at the time of hospital admission, and with daily visits to the care of the fractured older adults. ${ }^{4}$ This approach demonstrated to reduce the length of in-hospital stay and the number of medical complications in hip fracture patients, compared to the traditional model. ${ }^{4,5}$

The beneficial effects on short- and longterm outcomes of geriatric consultant in the orthopedic ward model have been evaluated in a meta-analysis recently published, including ten studies and more than 3000 patients presenting with hip fracture (with 1733 subjects undergoing the intervention protocol and 2025 subjects undergoing standard care). ${ }^{6}$ The meta-analysis demonstrated a significant decrease in long-term mortality [relative risk (RR), 0.78; 95\% confidence interval $(95 \% \mathrm{CI})$, 0.65-0.95], in-hospital mortality (RR, 0.51; 95\%CI, 0.38-0.69), and time to surgery [standardized mean difference (SMD) between the traditional and innovative model, $0.13 ; 95 \% \mathrm{CI}$, 0.23 to 0.03 ]. Only very few studies described data about functional recovery or in-hospital complications, reporting a positive effect on the incidence of post-operative delirium and in functional improvements.

Summarizing available evidence, the implementation of a geriatric consultant team in the orthopedic ward seems to add some benefits to the traditional model of care, only when the multidisciplinary team is involved early in the process of care. Although this model has the largest amount of studies published, more evidence are needed, and the results of available trials and meta-analysis should be interpreted with caution due to the extreme heterogeneity of the published trials, to the relatively small sample sizes of some of them, and to some differences between the geriatric consultant models implemented.

\section{Geriatric-orthopedic co-managed care}

This is probably the most sophisticated model implemented for the management of fractured older adults. It has been developed in different countries, mainly in North America and Europe, and it has evolved over the last 10 to 15 years with gradual improvements added with time..$^{3,18,19,21,26,28,34,38-46}$ The reference model of the geriatric-orthopedic co-managed care is the GFC developed at the University of Rochester (New York). 18,34 The key and characterizing element is the co-management of the fractured patients by a geriatrician and an orthopedic surgeon (orthogeriatric team) that share the responsibility and the leadership from the admission in the orthogeriatric unit to discharge. ${ }^{4,8}$ An interdisciplinary team including several healthcare professionals skilled in the care of geriatric orthopedic patients supports this co-direction. Standardized patient-centered, protocol-driven treatments and pathways are implemented.

The two healthcare figures directly involved (geriatrician and surgeon) visit the patient daily, write their own orders and communicate frequently, thus reducing the risk of delays, inappropriate care and iatrogenic errors, and promoting an optimal clinical coordination. ${ }^{4}$ Also orders and choices that traditionally are of surgical competence, such as timing of surgery or surgical agenda, are shared and discussed, to optimize the management of the patients. ${ }^{4}$

The beneficial effects on short- and longterm functional and clinical outcomes of this innovative model have been illustrated in a number of well-designed before-after observational studies and RCTs, in their reviews and meta-analyses. ${ }^{4-7,45}$ Table 2 and 3 describes most relevant studies published in the last fifteen years. For the sake of simplicity, in Table 2 are described studies reporting only in-hospital outcomes, ${ }^{18,19,39-42}$ while in Table 3 are depicted those describing short- and long-term outcomes. ${ }^{3,26,33,43,44,46}$ Trials are quite heterogeneous in terms of design, duration of follow-up and outcomes considered. In most of them, the implementation of a geriatric-orthopedic comanaged care model for the elderly patients with HF demonstrated to offer many benefits to the patients, reducing short- and long-term adverse events. Overall, the results of the different studies were not always consistent and sometimes skewed. Essentially, the geriatricorthopedic co-managed care model demonstrated consistently to reduce short- and longterm mortality and in-hospital complication, ${ }^{3,18,19,39,42,43,46}$ and, in one RCT, to improve functional outcomes, ${ }^{43}$ compared to the traditional model where only the orthopedic staff

Table 1. Models of integrated care for the management of the older adults presenting with fragility fracture: main features.

\begin{tabular}{lccc} 
Models of integrated care & Setting & Leadership & Consultative service \\
Traditional model & Orthopedic ward & Orthopedic Surgeon & Medical service on request \\
Geriatric consultant in the orthopedic ward & Orthopedic ward & Orthopedic Surgeon & Geriatric team with regular input \\
\hline Geriatric-orthopedic co-managed care & Ortho-geriatric unit & Orthopedic Surgeon and Geriatrician & None (interdisciplinary team) \\
Geriatric-led fracture service with orthopedic consultant & Geriatric ward & Geriatrician & Orthopedic Surgeon \\
\hline
\end{tabular}


was responsible of the management of the patient. For example, in two trials (one RCT and one before-after observational trial), the one-year survival rates were about $10 \%$ higher in the geriatric orthopedic co-managed care group than in the controls. ${ }^{3,43}$ Vidan et al. ${ }^{43}$ also reported, after adjustment for confounding variables, a significant $45 \%$ lower probability of death or major complications with their model of co-managed care.

In their meta-analysis including five studies and around 1800 patients with HF (955 undergoing the intervention protocol and 905 treated with standard care), Grigoryan et al. ${ }^{6}$ demonstrated a shortened length of in-hospital stay (SMD, $0.61 ; 95 \% \mathrm{CI}, 0.95$ to 0.28 ) and a reduced incidence of in-hospital complications with the geriatric orthopedic co-managed care. The very small number of studies included and the relevant heterogeneity strongly hampered the possibility to demonstrate significant beneficial effects on other short and long-term outcomes.

In conclusion, the geriatric orthopedic comanaged care service represents a valuable and more effective alternative to the traditional programs in the acute and post-acute management of HF older adults. Due to its complexity, the implementation of such services requests considerable efforts, consistent administrative support and strong physician leadership. ${ }^{4}$

\section{Geriatric-led fracture service with orthopedic consultant}

The overall management and healthcare pathway take place in a geriatric ward, under the complete responsibility of the geriatrician. ${ }^{4}$ The central role of the geriatrician as the primary attending physician for all patients from hospital

Table 2. Geriatric-orthopedic co-managed care service: studies evaluating in-hospital outcomes.

\begin{tabular}{|c|c|c|c|c|c|c|c|}
\hline Study design & & $\begin{array}{l}\text { Khasraghi } \\
\text { (US) } \\
\text { Before-after } \\
\text { retrospective }\end{array}$ & $\begin{array}{l}\text { Friedman ( } \\
\text { (US) }^{18} \\
\text { Retrospective } \\
\text { cohorts }\end{array}$ & $\begin{array}{l}\text { Gonzalez-Montalv } \\
\text { (SP) } \\
\text { e Randomized- } \\
\text { controlled }\end{array}$ & $\begin{array}{l}\text { vo Biber } \\
\text { (GER) } \\
\text { Before-after } \\
\text { retrospective }\end{array}$ & $\begin{array}{c}\text { Zeltzer } \\
(\text { AUS) } \\
\text { Retrospective } \\
\text { multicenter }\end{array}$ & $\begin{array}{c}\text { Flikweert } \\
(\mathrm{NL})^{19} \\
\text { Before-after } \\
\text { prospective }\end{array}$ \\
\hline Number of patients & $\begin{array}{l}\text { Intervention } \\
\text { Control }\end{array}$ & $\begin{array}{l}273 \\
237\end{array}$ & $\begin{array}{l}193 \\
121\end{array}$ & $\begin{array}{l}101 \\
123\end{array}$ & $\begin{array}{l}114 \\
169\end{array}$ & $\begin{array}{l}4575 \\
5026\end{array}$ & $\begin{array}{l}256 \\
145\end{array}$ \\
\hline Mean age (years) & $\begin{array}{l}\text { Intervention } \\
\text { Control }\end{array}$ & $\begin{array}{l}80 \\
80\end{array}$ & $\begin{array}{c}85^{*} \\
82 \\
\end{array}$ & $\begin{array}{l}85 \\
87 \\
\end{array}$ & $\begin{array}{l}82 \\
82 \\
\end{array}$ & $\begin{array}{l}84 \\
84 \\
\end{array}$ & $\begin{array}{l}78 \\
80 \\
\end{array}$ \\
\hline In-hospital mortality (\%) & $\begin{array}{l}\text { Intervention } \\
\text { Control }\end{array}$ & $\begin{array}{l}\text { NA } \\
\text { NA }\end{array}$ & $\begin{array}{l}1.6 \\
2.5\end{array}$ & $\begin{array}{l}5.9 \\
6.5\end{array}$ & $\begin{array}{l}4.4 \\
5.9\end{array}$ & $\begin{array}{c}6.5^{*} \\
8.1\end{array}$ & $\begin{array}{c}2.0 * \\
5.5\end{array}$ \\
\hline Length of stay [mean days (SD or IQR)] & $\begin{array}{l}\text { Intervention } \\
\text { Control }\end{array}$ & $\begin{array}{l}6(\mathrm{NR})^{*} \\
8(\mathrm{NR})\end{array}$ & $\begin{array}{l}5(3)^{*} \\
8(6)\end{array}$ & $\begin{array}{c}12(4)^{*} \\
18(8)\end{array}$ & $\begin{array}{l}14(7)^{*} \\
17(10)\end{array}$ & $\begin{array}{c}30(23)^{*} \\
29(30)\end{array}$ & $\begin{array}{l}7(6-10)^{*} \\
11(7-16)\end{array}$ \\
\hline Time to surgery [mean days (SD or IQR)] & $\begin{array}{l}\text { Intervention } \\
\text { Control }\end{array}$ & $\begin{array}{c}1.1(\mathrm{NR})^{*} \\
1.9(\mathrm{NR})\end{array}$ & $\begin{array}{c}1.0(0.7)^{*} \\
1.6(2.7)\end{array}$ & $\begin{array}{l}5(3-6)^{*} \\
6(5-9)\end{array}$ & $\begin{array}{l}2.1(1.8)^{*} \\
3.1(4.6)\end{array}$ & $\begin{array}{c}1.8(2.7) \\
1.7(13.2)\end{array}$ & $\begin{array}{l}\text { NR } \\
\text { NR }\end{array}$ \\
\hline In-hospital complications (\%) & $\begin{array}{l}\text { Intervention } \\
\text { Control }\end{array}$ & $\begin{array}{c}36^{*} \\
51\end{array}$ & $\begin{array}{c}31 * \\
46\end{array}$ & $\begin{array}{l}\mathrm{NA} \\
\mathrm{NA}\end{array}$ & $\begin{array}{l}\text { NA } \\
\text { NA }\end{array}$ & $\begin{array}{l}\text { NA } \\
\text { NA }\end{array}$ & $\begin{array}{l}51 \\
49\end{array}$ \\
\hline
\end{tabular}

US, United States; SP, Spain; GER, Germany; AUS, Australia; NL, the Netherlands; NA, not assessed; SD, standard deviation; IQR, interquartile range; NR, data assessed but not reported. *Statistical significant difference between intervention group and control group.

Table 3. Geriatric-orthopedic co-managed care service: studies evaluating short- and long-term outcomes.

\begin{tabular}{|c|c|c|c|c|c|c|c|}
\hline Study design & & $\begin{array}{c}\text { Vidan } \\
(\mathrm{SP})^{43} \\
\text { Randomized- } \\
\text { controlled }\end{array}$ & $\begin{array}{c}\text { Barone } \\
\text { (IT) }^{3} \\
\text { Before-after } \\
\text { prospective }\end{array}$ & $\begin{array}{c}\text { Cogan }^{\circ} \\
\text { (IR) }^{26} \\
\text { Before-after } \\
\text { retrospective }\end{array}$ & $\begin{array}{l}\text { Gregersen } \\
(\mathrm{DK})^{33} \\
\text { Before-after } \\
\text { retrospective }\end{array}$ & $\begin{array}{c}\text { Watne } \\
\text { (NOR) }^{44} \\
\text { Randomized- } \\
\text { controlled }\end{array}$ & $\begin{array}{c}\text { Suhm } \\
(\mathrm{SW})^{46} \\
\text { Before-after } \\
\text { prospective }\end{array}$ \\
\hline Number of patients & $\begin{array}{l}\text { Intervention } \\
\text { Control }\end{array}$ & $\begin{array}{l}155 \\
164\end{array}$ & $\begin{array}{l}272 \\
252\end{array}$ & $\begin{array}{c}98 \\
103\end{array}$ & $\begin{array}{l}233 \\
262\end{array}$ & $\begin{array}{l}163 \\
166\end{array}$ & $\begin{array}{l}224 \\
269\end{array}$ \\
\hline Mean age (years) & $\begin{array}{l}\text { Intervention } \\
\text { Control }\end{array}$ & $\begin{array}{l}81 \\
83 \\
\end{array}$ & $\begin{array}{l}84 \\
84 \\
\end{array}$ & $\begin{array}{c}82 * \\
75 \\
\end{array}$ & $\begin{array}{l}83 \\
82 \\
\end{array}$ & $\begin{array}{l}84 \\
85 \\
\end{array}$ & $\begin{array}{l}84 \\
84 \\
\end{array}$ \\
\hline In-hospital mortality (\%) & $\begin{array}{l}\text { Intervention } \\
\text { Control }\end{array}$ & $\begin{array}{c}0.6^{*} \\
5.5\end{array}$ & $\begin{array}{c}4.8^{*} \\
9.9\end{array}$ & $\begin{array}{c}8.2 \\
20.4\end{array}$ & $\begin{array}{l}7.7 \\
6.1\end{array}$ & $\begin{array}{l}3.7 \\
1.8\end{array}$ & $\begin{array}{l}1.8 \\
2.2\end{array}$ \\
\hline 12-month mortality (\%) & $\begin{array}{l}\text { Intervention } \\
\text { Control }\end{array}$ & $\begin{array}{l}18.9 \\
25.6\end{array}$ & $\begin{array}{c}25.0^{*} \\
35.3\end{array}$ & $\begin{array}{l}33.7 \\
44.6 \\
\end{array}$ & $\begin{array}{l}\text { NA } \\
\text { NA }\end{array}$ & $\begin{array}{l}28.2 \\
25.9\end{array}$ & $\begin{array}{c}28.6^{*} \\
19.7\end{array}$ \\
\hline Length of stay [mean days (SD or IQR)] & $\begin{array}{l}\text { Intervention } \\
\text { Control }\end{array}$ & $\begin{array}{l}16(5) \\
18(8)\end{array}$ & $\begin{array}{l}21(11) \\
21(13)\end{array}$ & $\begin{array}{l}30 \text { (NR) } \\
23 \text { (NR) }\end{array}$ & $\begin{array}{c}13(\mathrm{NR})^{*} \\
15(\mathrm{NR})\end{array}$ & $\begin{array}{c}11(8-15)^{*} \\
8(5-11)\end{array}$ & $\begin{array}{l}9(4)^{*} \\
11(5)\end{array}$ \\
\hline Time to surgery [mean days (SD or IQR)] & $\begin{array}{l}\text { Intervention } \\
\text { Control }\end{array}$ & $\begin{array}{l}3.2(1.8) \\
3.3(2.2)\end{array}$ & $\begin{array}{l}\text { NA } \\
\text { NA }\end{array}$ & $\begin{array}{l}1.9(0.9) \\
1.9(1.9)\end{array}$ & $\begin{array}{c}0.9(0.8)^{*} \\
0.7(1.0)\end{array}$ & $\begin{array}{l}1.1(0.7-1.8) \\
1.0(0.7-1.6)\end{array}$ & $\begin{array}{l}1.3(1.2) \\
1.2(1.0)\end{array}$ \\
\hline In-hospital complications (\%) & $\begin{array}{l}\text { Intervention } \\
\text { Control }\end{array}$ & $\begin{array}{c}45^{*} \\
62\end{array}$ & $\begin{array}{l}\text { NA } \\
\text { NA }\end{array}$ & $\begin{array}{l}\mathrm{NA} \\
\mathrm{NA}\end{array}$ & $\begin{array}{l}\text { NA } \\
\text { NA }\end{array}$ & $\begin{array}{l}44 \\
46\end{array}$ & $\begin{array}{c}59 * \\
73\end{array}$ \\
\hline Functional status recovery 3 month (\%) & $\begin{array}{l}\text { Intervention } \\
\text { Control }\end{array}$ & $\begin{array}{c}57^{*} \\
44\end{array}$ & $\begin{array}{l}\mathrm{NA} \\
\mathrm{NA}\end{array}$ & $\begin{array}{l}\mathrm{NA} \\
\mathrm{NA}\end{array}$ & $\begin{array}{l}\text { NA } \\
\text { NA }\end{array}$ & $\begin{array}{l}\mathrm{NA} \\
\mathrm{NA}\end{array}$ & $\begin{array}{l}\text { NA } \\
\text { NA }\end{array}$ \\
\hline
\end{tabular}

SP, Spain; IT, Italy; IR, Ireland; DK, Denmark; NOR, Norway; SW, Sweden; NA, not assessed; SD, standard deviation; IQR, interquartile range; NR, data assessed but not reported. *Statistical significant difference between intervention group and control group. ${ }^{\circ}$ The Authors did not reported the statistical significance in the between groups comparisons. 
admission to discharge distinguishes the service. ${ }^{4,5}$ The geriatrician evaluates the patient on admission and during in-hospital stay, coordinates the timing of surgery, procedures, diagnostics, treatments and transition/discharge planning. The geriatrician, the orthopedic surgeon and the anesthesiologist manage together the patients in the pre- and peri-operative phase, while, during the post-operative phase, the orthopedic surgeon is a consulting physician that follows the patients until complete wound healing. An interdisciplinary team, including different healthcare professionals, is integrated in the service. Standardized orders and protocols are implemented.

Usually, the hip fracture patient is admitted directly from the emergency department to the geriatric ward, where he/she is evaluated and prepared for surgery, transferred to the operating room and then returned to the geriatric ward. The post-acute rehabilitative phase may take place in the same setting under the healthcare of the same geriatric interdisciplinary team, ${ }^{24,47,48}$ or in the community within a skilled nursing facility. ${ }^{49}$

The reference model of the geriatric-led fracture service with orthopedic consultant is the Sheba model implemented by Adunsky and colleagues in 1999 (Israel). ${ }^{24,47,48}$ More recently, similar services have been adopted also in United Kingdom, United States and Europe. ${ }^{12,49-52}$

In Table $4^{12,16,46-49,52}$ are depicted relevant studies designed to evaluate the geriatric-led fracture service. In contrast to the wealth of data published for the other models described, information regarding the efficacy of the geriatric-led fracture service is relatively limited. The model originally proposed by Adunsky et $a l$, and recently implemented in other
Countries, demonstrated to improve the longterm functional outcomes, ${ }^{12,47,52}$ and, in some cases, to reduce time to surgery and in-hospital stay, compared to the traditional orthopedic-centered approach. ${ }^{4,5,24,47,48,52}$ On the other hand, none of the trials published to date, reported a consistent and significant reduction in short- and long-term mortality (Table 4).

In the geriatrician-led hip fracture program developed in Portland (Oregon, United States) by Miura et al., the HF subject is rapidly transferred to a community skilled-nursing facility early after surgery (3 days) for further rehabilitation, with a mean LOS lower than 5 days. ${ }^{49}$ This approach, alternative to the Sheba model, demonstrated to reduce significantly the direct and indirect cost.

In conclusion, on the basis of available evidence, a geriatrician-led fracture service with orthopedic consultant approach seems feasible, applicable and effective in terms of functional outcomes, when the overall care takes place in the same setting. ${ }^{4}$ The beneficial effects of a the model in which the geriatric leadership is limited to the acute phase still need to be established, although a separation of the intensity of care from the acute to the post-acute phase seems economically more suitable.,49

\section{Early supported discharge and post-acute care}

\section{General considerations}

The concept of using forms of intermediate care, such as skilled nursing or community facilities and early home-based rehabilitation, to allow earlier discharge from the acute ward, has been introduced in the United States many years ago and more recently adopted also in UK and other European Countries.,22 The main objectives of these post-acute care services were to alleviate the pressure on hospital bed capacity, to reduce LOS and to promote earlier discharge, while maintaining an acceptable quality of care and without worsening short- and long-term outcomes. ., $, 5,54,53^{-1}$

For hip fracture older adults, home-based supported rehabilitation (HBR) and geriatric orthopedic rehabilitation units (GORU) represented the more consistently implemented approaches to face these needs. ${ }^{2,453-57}$

These innovative schemes should be considered as possible post-acute transitions that could be used in tandem with any of the aforementioned models, rather than a real and comprehensive model of care for the management of HF older adults, since they interest only a part of the overall healthcare pathway of $\mathrm{HF}$ patients. ${ }^{4}$ Indeed, the implementation of these services without a model including an early intervention may not produce the expected benefits. ${ }^{4}$

\section{Home-based supported rehabilitation}

Early discharge and HBR after hip fracture have been developed since 1986 in Europe, Australia and North America. ${ }^{4}$ The implementation of this service requires adequate community resources, and, in particular, the presence of hospital at home community nursing services in the healthcare district where the program is introduced. To be suitable for early discharge and HBR, subjects should be com-

Table 4. Geriatric-led fracture service with orthopedic consultant: studies evaluating short- and long-term outcomes.

\begin{tabular}{|c|c|c|c|c|c|c|c|}
\hline Study design & & $\begin{array}{c}\text { Stenvall } \\
(\mathrm{SW})^{52} \\
\text { Randomized- } \\
\text { controlled }\end{array}$ & $\begin{array}{c}\text { Miura } \\
\text { (US) } \\
\text { Before-after }^{\circ} \\
\text { prospective }\end{array}$ & $\begin{array}{c}\text { Adunsky } \\
(\text { ISR) } \\
\text { Ret,48 } \\
\text { Retrospective } \\
\text { cohort }\end{array}$ & $\begin{array}{l}\text { Della Rocca } \\
\text { (US) }{ }^{46} \\
\text { Before-after } \\
\text { retrospective }\end{array}$ & $\begin{array}{l}\text { Boddaert } \\
\text { (FR) }^{16} \\
\text { Prospective } \\
\text { cohorts }\end{array}$ & $\begin{array}{c}\text { Prestmo } \\
(\text { NOR) } \\
\text { Randomized- } \\
\text { controlled }\end{array}$ \\
\hline Number of patients & $\begin{array}{l}\text { Intervention } \\
\text { Control }\end{array}$ & $\begin{array}{c}102 \\
97\end{array}$ & $\begin{array}{l}91 \\
72\end{array}$ & $\begin{array}{l}847 \\
2267\end{array}$ & $\begin{array}{c}115 \\
31\end{array}$ & $\begin{array}{l}203 \\
131\end{array}$ & $\begin{array}{l}198 \\
199\end{array}$ \\
\hline Mean age (years) & $\begin{array}{l}\text { Intervention } \\
\text { Control }\end{array}$ & $\begin{array}{l}82 \\
82\end{array}$ & $\begin{array}{l}80 \\
81\end{array}$ & $\begin{array}{l}82^{*} \\
81\end{array}$ & $\begin{array}{l}82 \\
82\end{array}$ & $\begin{array}{l}86 \\
85\end{array}$ & $\begin{array}{l}83 \\
83\end{array}$ \\
\hline In-hospital mortality (\%) & $\begin{array}{l}\text { Intervention } \\
\text { Control }\end{array}$ & $\begin{array}{l}5.9 \\
7.2\end{array}$ & $\begin{array}{l}\mathrm{NA} \\
\mathrm{NA}\end{array}$ & $\begin{array}{l}1.9 \\
3.0\end{array}$ & $\begin{array}{l}4.3 \\
9.7\end{array}$ & $\begin{array}{l}3.0 \\
7.6\end{array}$ & $\begin{array}{l}\text { NR } \\
\text { NR }\end{array}$ \\
\hline Long-term mortality (\%) & $\begin{array}{l}\text { Intervention } \\
\text { Control }\end{array}$ & $\begin{array}{l}15.7 \\
18.6\end{array}$ & $\begin{array}{l}\mathrm{NA} \\
\mathrm{NA}\end{array}$ & $\begin{array}{l}14.8 \\
17.3\end{array}$ & $\begin{array}{l}31.3 \\
45.2\end{array}$ & $\begin{array}{l}14.3 \\
23.7\end{array}$ & $\begin{array}{l}15.2 \\
18.6\end{array}$ \\
\hline Length of stay [mean days (SD or IQR)] & $\begin{array}{l}\text { Intervention } \\
\text { Control }\end{array}$ & $\begin{array}{c}30(18)^{*} \\
40(41)\end{array}$ & $\begin{array}{l}5(1)^{*} \\
6(2)\end{array}$ & $\begin{array}{c}32(20)^{*} \\
25(31)\end{array}$ & $\begin{array}{l}7(\mathrm{NR})^{*} \\
10(\mathrm{NR})\end{array}$ & $\begin{array}{l}11(8-16)^{*} \\
13(10-20)\end{array}$ & $\begin{array}{c}13(0.4)^{*} \\
11(0.5)\end{array}$ \\
\hline Time to surgery [mean days (SD or IQR)] & $\begin{array}{l}\text { Intervention } \\
\text { Control }\end{array}$ & $\begin{array}{l}1.0(0.7) \\
1.0(0.6)\end{array}$ & $\begin{array}{l}\text { NA } \\
\text { NA }\end{array}$ & $\begin{array}{c}3.0(2.9)^{*} \\
2.9(6.5)\end{array}$ & $\begin{array}{l}1.2 \text { (NR) } \\
1.5 \text { (NR) }\end{array}$ & $\begin{array}{l}0.9(0.5-1.4) \\
1.0(0.6-1.7)\end{array}$ & $\begin{array}{l}1.2(1.1) \\
1.2(0.9)\end{array}$ \\
\hline $\begin{array}{l}\text { Discharge to pre-admission place } \\
\text { of residence (\%) }\end{array}$ & $\begin{array}{l}\text { Intervention } \\
\text { Control }\end{array}$ & $\begin{array}{l}84 \\
76\end{array}$ & $\begin{array}{l}\text { NA } \\
\text { NA }\end{array}$ & $\begin{array}{l}\text { NA } \\
\text { NA }\end{array}$ & $\begin{array}{l}\text { NA } \\
\text { NA }\end{array}$ & $\begin{array}{l}\text { NR } \\
\text { NR }\end{array}$ & $\begin{array}{c}25^{*} \\
11\end{array}$ \\
\hline
\end{tabular}

SW, Sweden; US, United States; ISR, Israel; FR, France, NOR, Norway; NA, not assessed; NR, data assessed but not reported; SD, standard deviation; IQR, interquartile range. *Statistical significant difference between intervention group and control group. ${ }^{\circ}$ The Authors did not reported the statistical significance in the between groups comparisons. 
munity dwelling, living with relatives or other informal support, and clinically stable without any relevant acute illness..$^{2,4,53}$

The patient is usually assessed on admission for eligibility, and to set up a discharge planning. Early after surgery, the patient is transferred directly home for rehabilitation. An interdisciplinary team, including a geriatrician, a geriatric nurse and a physical therapist, is usually involved in the care of the older adult in collaboration with the general practitioner. ${ }^{4}$

A number of RCTs and prospective observational studies have evaluated the potential beneficial effects of HBR.,2,53,55,58-62 Published studies demonstrated that HBR services in elderly patients after hip fracture are feasible, safe and effective producing comparable results in terms of functional outcomes, and reducing length of in-hospital stay compared to traditional programs. ${ }^{4}$ These results were confirmed also when patients with pre-fracture cognitive decline or disability were considered suitable for these programs. ${ }^{2,53}$

\section{Geriatric orthopedic rehabilitation units}

The GORU is a variation of the traditional geriatric rehabilitation unit, fully dedicated to the care of older adults presenting with a fragility fracture.

In general, once the orthopedic surgeon, the geriatrician or the orthogeriatric team judges that the patient is medically fit to be moved to a rehabilitation ward, he/she is rapidly transferred to a GORU. ${ }^{4}$ Basically, the presence of a geriatrician as supervisor and leader, supported by a multidisciplinary team, distinguishes this service from other rehabilitation programs.

The GORU demonstrated to produce shortand long-term better outcomes compared to traditional rehabilitation units. In several welldesigned trials, patients admission to GORU after hip fracture produced a significant reduction in length of stay, a greater recovery of functional status, a lower risk of institutionalization and a higher rate of survival. . $2,56-58,63,64$ Finally, it should be emphasized that this rehabilitation approach demonstrated to be really successful also in patients with moderate to severe dementia. ${ }^{64}$

\section{Conclusions}

In this narrative overview we have characterized and described a number of innovative models of care for the management of older adults with hip fracture. These services were distinguished mainly on the basis of the role of the healthcare professionals involved in the healthcare pathway, with particular attention to the figure (orthopedic surgeon or geriatrician) that retains the responsibility and leadership throughout the clinical pathway.

The HF services implemented in the different countries are quite heterogeneous, and frequently represent a combination of different models. The development and implementation of a service for HF management should, in fact, consider the best available evidence, but also existing resources, willingness to pay and actual local organization of the healthcare system. ${ }^{4}$

Relevant differences in the trials interventions, populations and outcomes hamper our ability to define which model, setting and care organization is the optimal, or superior to the others, in terms of short- and long-term outcomes. However, our review underlines a tendency to better overall outcomes in patients receiving the more complex approach based on the co-management of the patient. On the other hand, it should be emphasized that there is still insufficient evidence to draw conclusions about how effective these models are for patients with pre-fracture cognitive decline (or severe disability), as recently highlighted in a review/meta-analysis about rehabilitation and care models for $\mathrm{HF}$ older adults with dementia. ${ }^{65}$

\section{References}

1. Pioli G, Barone A, Giusti A, et al. Predictors of mortality after hip fracture: results from 1-year follow-up. Aging Clin Exp Res 2006; 18:381-7.

2. Giusti A, Barone A, Oliveri M, et al. An analysis of the feasibility of home rehabilitation among elderly people with proximal femoral fractures. Arch Phys Med Rehabil 2006;87:826-31.

3. Barone A, Giusti A, Pizzonia M, et al. A comprehensive geriatric intervention reduces short- and long-term mortality in older people with hip fracture. J Am Geriatr Soc 2006;54:711-2.

4. Giusti A, Barone A, Razzano M, et al. Optimal setting and care organization in the management of older adults with hip fracture. Eur J Phys Rehabil Med 2011;47: 281-96.

5. Pioli G, Giusti A, Barone A. Orthogeriatric care for the elderly with hip fractures: where are we? Aging Clin Exp Res 2008; 20:113-22.

6. Grigoryan KV, Javedan H, Rudolph JL. Orthogeriatric care models and outcomes in hip fracture patients: a systematic review and meta-analysis. J Orthop Trauma 2014;28:e49-55.

7. Buecking B, Timmesfeld N, Riem S, et al. Early orthogeriatric treatment of trauma in the elderly: a systematic review and meta-analysis. Dtsch Arztebl Int 2013;110: 255-62.

8. Mendelson DA, Friedman SM. Principles of comanagement and the geriatric fracture center. Clin Geriatr Med 2014;30:183-89.

9. Doshi HK, Ramason R, Azellarasi J, et al. Orthogeriatric model for hip fracture patients in Singapore: our early experience and initial outcomes. Arch Orthop Trauma Surg 2014;134:351-7.

10. Fisher AA, Davis MW, Rubenach SE, et al. Outcomes for older patients with hip fractures: the impact of orthopedic and geriatric medicine cocare. J Orthop Trauma 2006;20:172-8.

11. Marcantonio ER, Flacker JM, Wright RJ, et al. Reducing delirium after hip fracture: a randomized trial. J Am Geriatr Soc 2001; 49:516-22.

12. Prestmo A, Hagen G, Sletvold 0, et al. Comprehensive geriatric care for patients with hip fractures: a prospective, randomised, controlled trial. Lancet 2015;385: 1623-33.

13. Martinez-Reig M, Ahmad L, Duque G. The orthogeriatrics model of care: systematic review of predictors of institutionalization and mortality in post-hip fracture patients and evidence for interventions. J Am Med Dir Assoc 2012;13:770-7.

14. Vitale E, Notarnicola A, Tafuri S, et al. Orthopedic multidimensional prognostic index (Ortho-MPI) in the elderly with hip or neck fracture: a pilot study. Arch Gerontol Geriatr 2014;58:101-4.

15. Pioli G, Barone A, Mussi C, et al. The management of hip fracture in the older population. Joint position statement by Gruppo Italiano Ortogeriatria (GIOG). Aging Clin Exp Res 2014;26:547-53.

16. Boddaert J, Cohen-Bittan J, Khiami F, et al. Postoperative admission to a dedicated geriatric unit decreases mortality in elderly patients with hip fracture. PLoS One 2014;9:e83795.

17. Gehlbach SH, Avrunin JS, Puleo E. Trends in hospital care for hip fractures. Osteoporos Int 2007;18:585-91.

18. Friedman SM, Mendelson DA, Bingham $\mathrm{KW}$, et al. Impact of a comanaged geriatric fracture center on short-term hip fracture outcomes. Arch Intern Med 2009;169: 1712-7.

19. Flikweert ER, Izaks GJ, Knobben BA, et al. The development of a comprehensive multidisciplinary care pathway for patients with a hip fracture: design and results of a clinical trial. BMC Musculoskelet Disord 2014;15:188.

20. Chia PH, Gualano L, Seevanayagam S, et al. Outcomes following fractured neck of femur in an Australian metropolitan teaching hospital. Bone Joint Res 2013;2: $162-8$. 
21. Bhattacharyya R, Agrawal Y, Elphick H, et al. A unique orthogeriatric model: a step forward in improving the quality of care for hip fracture patients. Int J Surg 2013; 11:1083-6.

22. Jarman B, Aylin P, Bottle A. Discharge destination and length of stay: differences between US and English hospitals for people aged 65 and over. BMJ 2004;328:605.

23. The National Hip Fracture Database. National Report 2012. Available from: http://www.nhfd.co.uk/20/hipfractureR.nsf/ vwcontent/2012ReportDownload/\$File/NH FD+National+Report+2012.pdf?openelement Accessed: October 1, 2015.

24. Adunsky A, Arad M, Levi R, et al. Five-year experience with the 'Sheba' model of comprehensive orthogeriatric care for elderly hip fracture patients. Disabil Rehabil 2005;27:1123-7.

25. Alvarez-Nebreda ML, Vidan MT, Serra JA. Hip fracture management and outcomes in Spain. Eur Geriatr Med 2010;1:108-11.

26. Cogan L, Martin AJ, Kelly LA, et al. An audit of hip fracture services in the Mater Hospital Dublin 2001 compared with 2006. Ir J Med Sci 2010;179:51-5.

27. Deschodt M, Braes T, Broos P, et al. Effect of an inpatient geriatric consultation team on functional outcome, mortality, institutionalization, and readmission rate in older adults with hip fracture: a controlled trial. J Am Geriatr Soc 2011;59:1299-308.

28. Folbert EC, Smit RS, van der Velde D, et al. Geriatric fracture center: a multidisciplinary treatment approach for older patients with a hip fracture improved quality of clinical care and short-term treatment outcomes. Geriatr Orthop Surg Rehabil 2012; 3:59-67.

29. Auais M, Morin S, Nadeau L, et al. Changes in frailty-related characteristics of the hip fracture population and their implications for healthcare services: evidence from Quebec, Canada. Osteoporos Int 2013;24:2713-24.

30. Beaupre LA, Cinats JG, Senthilselvan A, et al. Reduced morbidity for elderly patients with a hip fracture after implementation of a perioperative evidence-based clinical pathway. Qual Saf Health Care 2006;15: 375-9.

31. Pioli G, Frondini C, Lauretani F, et al. Time to surgery and rehabilitation resources affect outcomes in orthogeriatric units. Arch Gerontol Geriatr 2012;55:316-22.

32. Pioli G, Lauretani F, Davoli ML, et al. Older people with hip fracture and IADL disability require earlier surgery. J Gerontol A Biol Sci Med Sci 2012;67:1272-7.

33. Gregersen M, Mørch MM, Hougaard K, et al. Geriatric intervention in elderly patients with hip fracture in an orthopedic ward. J Inj Violence Res 2012;4:45-51.
34. Kates SL, Mendelson DA, Friedman SM. Co-managed care for fragility hip fractures (Rochester model). Osteoporos Int 2010; 21:S621-5.

35. Sund R. Modeling the volume-effectiveness relationship in the case of hip fracture treatment in Finland. BMC Health Serv Res 2010;10:238.

36. Forte ML, Virnig BA, Swiontkowski MF, et al. Ninety-day mortality after intertrochanteric hip fracture: does provider volume matter? J Bone Joint Surg Am 2010; 92:799-806.

37. Gilchrist WJ, Newman RJ, Hamblen DL, et al. Prospective randomised study of an orthopaedic geriatric inpatient service. BMJ 1988;297:1116-8.

38. Khan R, Fernandez C, Kashifl F, et al. Combined orthogeriatric care in the management of hip fractures: a prospective study. Ann R Coll Surg Engl 2002;84:122-4.

39. Khasraghi FA, Christmas C, Lee EJ, et al. Effectiveness of a multidisciplinary team approach to hip fracture management. J Surg Orthop Adv 2005;14:27-31.

40. Gonzàlez-Montalvo JI, Alarcòn T, Mauleòn JL, et al. The orthogeriatric unit for acute patients: a new model of care that improves efficiency in the management of patients with hip fracture. Hip Int 2010;20:229-35.

41. Biber R, Singler K, Curschmann-Horter M, et al. Implementation of a co-managed Geriatric Fracture Center reduces hospital stay and time-to-operation in elderly femoral neck fracture patients. Arch Orthop Trauma Surg 2013;133:1527-31.

42. Zeltzer J, Mitchell RJ, Toson B, et al. Orthogeriatric services associated with lower 30-day mortality for older patients who undergo surgery for hip fracture. Med J Aust 2014;201:409-11.

43. Vidàn M, Serra JA, Moreno C, et al. Efficacy of a comprehensive geriatric intervention in older patients hospitalized for hip fracture: a randomized, controlled trial. J Am Geriatr Soc 2005;53:1476-82.

44. Watne LO, Torbergsen AC, Conroy S, et al. The effect of a pre- and postoperative orthogeriatric service on cognitive function in patients with hip fracture: randomized controlled trial (Oslo Orthogeriatric Trial). BMC Med 2014;12:63.

45. Kammerlander C, Roth T, Friedman SM, et al. Ortho-geriatric service--a literature review comparing different models. Osteoporos Int 2010;21:S637-46.

46. Suhm N, Kaelin R, Studer P, et al. Orthogeriatric care pathway: a prospective survey of impact on length of stay, mortality and institutionalisation. Arch Orthop Trauma Surg 2014;134:1261-9.

47. Adunsky A, Lusky A, Arad M, et al. A comparative study of rehabilitation outcomes of elderly hip fracture patients: the advan- tage of a comprehensive orthogeriatric approach. J Gerontol A Biol Sci Med Sci 2003;58:542-7.

48. Adunsky A, Lerner-Geva L, Blumstein T, et al. Improved survival of hip fracture patients treated within a comprehensive geriatric hip fracture unit, compared with standard of care treatment. J Am Med Dir Assoc 2011;12:439-44.

49. Miura LN, DiPiero AR, Homer LD. Effects of a geriatrician-led hip fracture program: improvements in clinical and economic outcomes. J Am Geriatr Soc 2009;57:159-67.

50. Della Rocca GJ, Moylan KC, Crist BD, et al. Comanagement of geriatric patients with hip fractures: a retrospective, controlled, cohort study. Geriatr Orthop Surg Rehabil 2013;4:10-5.

51. Gupta A. The effectiveness of geriatricianled comprehensive hip fracture collaborative care in a new acute hip unit based in a general hospital setting in the UK. J R Coll Physicians Edinb 2014;44:20-6.

52. Stenvall M, Olofsson B, Nyberg L, et al. Improved performance in activities of daily living and mobility after a multidisciplinary postoperative rehabilitation in older people with femoral neck fracture: a randomized controlled trial with 1-year followup. J Rehabil Med 2007;39:232-8.

53. Giusti A, Barone A, Pioli G. Rehabilitation after hip fracture in patients with dementia. J Am Geriatr Soc 2007;55:1309-10.

54. Parker MJ, Pryor GA, Myles J. 11-year results in 2,846 patients of the Peterborough hip fracture project: reduced morbidity, mortality and hospital stay. Acta Orthop Scand 2000;71:34-8.

55. Hollingworth W, Todd C, Parker M, et al. Cost analysis of early discharge after hip fracture. BMJ 1993;307:903-6.

56. Reid J, Kennie DC. Geriatric rehabilitative care after fractures of the proximal femur: one year follow up of a randomised clinical trial. BMJ 1989;299:25-6.

57. Kennie DC, Reid J, Richardson IR, et al. Effectiveness of geriatric rehabilitative care after fractures of the proximal femur in elderly women: a randomised clinical trial. BMJ 1988;297:1083-6.

58. Chudyk AM, Jutai JW, Petrella RJ, et al. Systematic review of hip fracture rehabilitation practices in the elderly. Arch Phys Med Rehabil 2009;90:246-62.

59. Crotty M, Whitehead $\mathrm{CH}$, Gray $\mathrm{S}$, et al. Early discharge and home rehabilitation after hip fracture achieves functional improvements: a randomized controlled trial. Clin Rehabil 2002;16:406-13.

60. Crotty M, Whitehead C, Miller M, et al. Patient and caregiver outcomes 12 months after home-based therapy for hip fracture: a randomized controlled trial. Arch Phys Med Rehabil 2003;84:1237-9. 
61. Kuisma R. A randomized, controlled comparison of home versus institutional rehabilitation of patients with hip fracture. Clin Rehabil 2002;16:553-61.

62. Tinetti ME, Baker DI, Gottschalk M, et al. Home-based multicomponent rehabilitation program for older persons after hip fracture: a randomized trial. Arch Phys Med Rehabil 1999;80:916-22.

63. Huusko TM, Karppi P, Avikainen V, et al. Intensive geriatric rehabilitation of hip fracture patients: a randomized, controlled trial. Acta Orthop Scand 2002;73:425-31.

64. Huusko TM, Karppi P, Avikainen V, et al. Randomised, clinically controlled trial of intensive geriatric rehabilitation in patients with hip fracture: subgroup analysis of patients with dementia. BMJ 2000; 321:1107-11.

65. Smith T0, Hameed YA, Cross JL, et al. Enhanced rehabilitation and care models for adults with dementia following hip fracture surgery. Cochrane Database Syst Rev 2015;6:CD010569. 